\title{
MODELLING THE DETERMINANTS OF EFFECTIVE ONLINE TUTORING PROGRAMS
}

\author{
Dr. Maximus Gorky SEMBIRING \\ Faculty of Education and Teacher Training \\ Universitas Terbuka \\ Tangerang Selatan, Indonesia
}

\begin{abstract}
Determinants of effective online tutoring program were modelled and elucidated in this report. It was aimed at clarifying influential factors, how and in what behaviors they were interrelated observed by Universitas Terbuka students. Exploratory-design was adopted; it was qualitatively ascertained first that conceptually five foremost factors involved. They were operationally instigated as: perception of technology, rational for using Internet, perception of media support; tutor learning strategy; effective online tutoring support. Quantitatively, they were independent, moderating and dependent variables respectively. Instruments in the form of list of queries and questionnaires for qualitative and quantitative purposes respectively were elaborated related to those five variables involved. Respondents were proportionally selected by distributing 600 questionnaires to 5,500 students under scholarship scheme, 283 were finally completed. Seven out of nine hypotheses established were validated using structural-equation model (SEM). It was detected that effective online tutorial was influenced by tutor learning strategy followed by rational for using Internet and perception of technology. Tutor strategy was influenced by rational using Internet and perception of technology. Perceptions of technology and media support were influenced by rational using Internet. Inattentively, qualitative approach was improperly verified by quantitative, since effective tutoring and tutor strategy were not influenced by media perception.
\end{abstract}

Keywords: Exploratory-design, online tutorial, tutor learning strategy, SEM.

\section{INTRODUCTION}

This study is an augmentation of comparable piece of work on the determinants of effectual online tutorial support in Open Distance Learning (ODL) setting as reported by Rustam, Haliman, Susanty, and Sembiring (2015) with modified initial operational framework and different respondents. This kind of study is still pertinent to be sustained as global stream of an online learning and its advantage as a result of how Internet technologies integrated well with ODL are extensively explored within this couple of decades. With an exponential advancement in information and communication technology (ICT), online tutorial has become increasingly well-liked approach for most of distance learners (Zang, Perris \& Yeung, 2005). This represents various prospects for the continued progression of ODL by providing current prospective students with larger flexibility and prospect for obtaining quality education (Devine \& Lokuge, 2012). Integration of Internet technologies will potentially enhance student connectivity in ODL ambience and strengthen the learning environment with emerging accepted technologies and tutor contributions (Susilo, 2014; Price, Richardson \& Jelfs, 2007), including on the online technology self-efficacy related to the type of media used (Kobayashi, 2017) .

Up to the mid of 1990's, including in Indonesia milieu, learner isolation issues have been revealed as a common problem in ODL framework and it is ordinarily remarked as the driving force of student dropout or attrition (Bean, 1985; Tinto, 1993; Sembiring, 2014). 
By a fastidious understanding, approaching to the end of 1990's, Universitas Terbuka familiarized the online tutorial services to bridge student gap in accessing and acquiring information, services, and academic supplies. The University has endorsed prominent roles within the country as well as in the neighboring regions by offering 179 courses through the online tutoring regularities as the beginning of a real online learning scheme. Since then more than 800 courses totaling of plausible courses offered have been switched into entirely or partly incorporated into online delivery mode (Universitas Terbuka, 2017). These numbers are complied harmoniously with respect to what was quantified in the University's strategic and operational plan earlier (Universitas Terbuka, 2015).

Student body in 2016 for instance was totaled to 297,897 . Given those facts, it is more likely that the number of students participating in this service would probably be approaching to a million student-course. These numbers come from calculating student takes three to four courses per semester. In realization nonetheless, around 600,000 student-course were participated during 2016 academic year (Universitas Terbuka, 2017). All the same, the final grade was contributed up to $30 \%$ from the online tutorial activities. It implies that the participation rate on this service was considered to be low.

It is therefore right to anticipate how the online tutorial service did support a flexible and rich learning environment to deliver a high quality and efficient ODL operations through Universitas Terbuka tradition. Additionally, there is a limited revelation in how to create and upgrade those tutorial supports substantively by means of online technologies so that the supports are entirely effective, accessible, and beneficial to all students as users. The study was therefore aimed at explicating variables and dimensions engaged that influencing to the effectiveness of the online tutoring scheme. It was also important to distinguish how all factors engaged were interrelated one another and in what behaviors. Investigation is guesstimated utilizing mixed methods, i.e., exploratory-design.

\section{THE CONCEPTUAL FRAMEWORK}

The significance of long-established traditional teaching and learning schemes has been challenged ever since as more educationalists are searching for alternate approaches of presenting learning materials, engaging more students, and concurrently increasing their academic performances. As a consequence, the use of both computers and Internet had become an integral part of teaching and learning process. This prologue is recapitulated by Guy and Lownes-Jackson (2012) and also adding to which that computers and Internet had facilitated the growth of online tutoring support as the media of learning for student across countless branches of disciplines.

Referring to the objective of the study, factors and associated dimensions of effective online tutorial supports are expansively investigated. Effectiveness of online tutorial is in general determined by various factors. Qualitatively, it was limited to four main factors, partially and comparatively inspired by Zhang, Perris and Yeung (2005), Rossel-Aguilar (2007), Shin and Kang (2015) and Mbatha (2015). They are: perception of technology, rational for using Internet, perception of media support and tutor learning strategy.

Effectual online tutorial support is referred to as having prearranged design (Mitchel, 2005), highly interactive (MacKinnon \& Williams, 2006), with quick-response feature (Varnhagen \& Digdon, 2002) and positively contributive to students final grade (Wilson \& Harris, 2002). Perception of technology is denoted of possessing comfortable and gainful procedure (Sweeny \& Ingram, 2004), promptness (Lee, Cortney \& Balassi, 2010), accuracy (Koch \& Gobel, 1999) and embeded traceability trait (Bliwise, 2005).

Rational for using Internet is described as retaining effectiveness or efficacy (Bolliger \& Supanakorn, 2011), accessibility (Jain, 2006), communication (Elicker, O'Malle \& Williams, 2008) and simplicity or easiness when utilized by students (Osborn, 2010). 
Perception of media support is expressed as preserving aspects on availability and friendliness (MacKinnon \& Williams, 2006), integration or methodical (Lenz, 2010) and connectedness (Talmadge \& Chitester, 2010). Tutor learning strategy is extracted to conserving discussion (Dawson, 1998), initiating group work (Cheng \& Swanson, 2010), the style of tutor in teaching and learning process (Benham, 2002; Keefe, 1979), and providing related referral sources (Talmadge \& Chitester, 2010) for rendering students appreciating the online tutoring sessions.

Having acknowledged and amalgamated the results as the follow up of interviews and focus group discussions with respect to the literature review accomplished in advance (as part of qualitative process), it comes to rectify them comprehensively. They are systematized to ease the establishment of the research framework as illustrated in Table 1. The ultimate of these processes will be ending up with the research framework and hypotheses that will be taken care of statistically afterward. This table is used as the basis of establishing the operational framework of the study for quantitative method.

Table 1. Variables and dimensions of the study

\begin{tabular}{|c|c|c|c|c|c|c|}
\hline No & Variables & Dimensions & No & Variables & Dimensions & Notes \\
\hline 1 & $\begin{array}{l}\text { Effective } \\
\text { online } \\
\text { tutorial } \\
\text { support } \\
\mathbf{Y}\end{array}$ & $\begin{array}{l}Y_{1}: \text { Contributive } \\
Y_{2}: \text { Interactive } \\
Y_{3} \text { : Responsive } \\
Y_{4} \text { : Prearranged }\end{array}$ & 2 & $\begin{array}{l}\text { Perception } \\
\text { of } \\
\text { technology } \\
\mathbf{X}_{1}\end{array}$ & $\begin{array}{l}\mathbf{X}_{11}: \text { Promptness } \\
\mathbf{X}_{12}: \text { Accuracy } \\
\mathbf{X}_{13}: \text { Traceability } \\
\mathbf{X}_{14}: \text { Gainful }\end{array}$ & \multirow{2}{*}{$\begin{array}{l}\text { Each } \\
\text { dimension is } \\
\text { measured by } \\
3 \text { questions; } \\
12 \text { questions } \\
\text { for each } \\
\text { variable }\end{array}$} \\
\hline 3 & $\begin{array}{c}\text { Rational for } \\
\text { using } \\
\text { Internet } \\
\mathbf{X}_{2}\end{array}$ & $\begin{array}{l}\mathbf{X}_{21}: \text { Accessibility } \\
X_{22}: \text { Easiness } \\
X_{23}: \text { Expansiveness } \\
X_{24}: \text { Efficacy }\end{array}$ & \multirow{2}{*}{4} & \multirow{2}{*}{$\begin{array}{l}\text { Perception } \\
\text { of media } \\
\text { support } \\
\mathbf{X}_{3}\end{array}$} & \multirow{2}{*}{$\begin{aligned} X_{31}: \text { Methodical } \\
X_{32}: \text { Friendly } \\
X_{33}: \text { Availability } \\
X_{34}: \text { Connected- } \\
\text { ness }\end{aligned}$} & \\
\hline 5 & $\begin{array}{l}\text { Learning } \\
\text { strategy of } \\
\text { tutor } \\
\mathrm{X}_{\mathbf{4}}\end{array}$ & $\begin{array}{l}\mathbf{X}_{41}: \text { Style } \\
X_{42}: \text { Group work } \\
X_{43}: \text { Referral source } \\
X_{44}: \text { Discussion }\end{array}$ & & & & $\begin{array}{l}\text { Total } \\
\text { questions: } 60\end{array}$ \\
\hline
\end{tabular}

Having considered the summary exhibited in Table 1, it is now on the right step to establish the operational framework and hypotheses of the study. The framework, as illustrated in Figure 1, will be analyzed afterwards under quantitative procedures with the help of structural-equation model (SEM). SEM is a multivariate statistical analysis technique that is utilized to analyze structural relationships. SEM is the combination of factor analysis and multiple regression analysis. It is applied to analyze structural relationship between measured variables and latent constructs. It is preferred by most researcher for it estimates the multiple and interrelated dependence in a single analysis.

\section{THE DESIGN AND HYPOTHESES}

This study is conducted following mixed methods, i.e., exploratory-design (Creswell \& Clark, 2011). The research is predetermined instigated using qualitative procedure first and then followed by quantitative series. Two kinds of instruments are prepared. The first is in the form of list of systematic and unified questions for in-depth interviews and focus group discussions for qualitative purpose. The second is an instrument in the form of questionnaire for quantitative purpose to gather required data from eligible respondents by survey. The ultimate objective of qualitative series is to establish the operational framework and hypotheses of the study as illustrated in Figure 1.

Figure 1, as an auxiliary elaboration of Table 1, authorized highlights of four identified variables influencing effective online tutorial support (as the dependent variable, $Y$ ). They are: perception of technology $\left(X_{1}\right)$, rational for using internet $\left(X_{2}\right)$, perception of media support $\left(X_{3}\right)$, and tutor learning strategy $\left(X_{4}\right)$; where $X_{1-3}$ and $X_{4}$ are the independent and moderating variables respectively. 
The quantitative instrument consisted of 60 questions; Likert Scale 1-5 and related to the five variables engaged. It implies that each variable has four dimensions and each dimension is measured by three questions. This approach is meant to quantitatively address the conceptual framework in operational level to be better organized on the model, design, hypotheses, survey and sampling techniques, data collection and analysis, and inferring the final remarks.

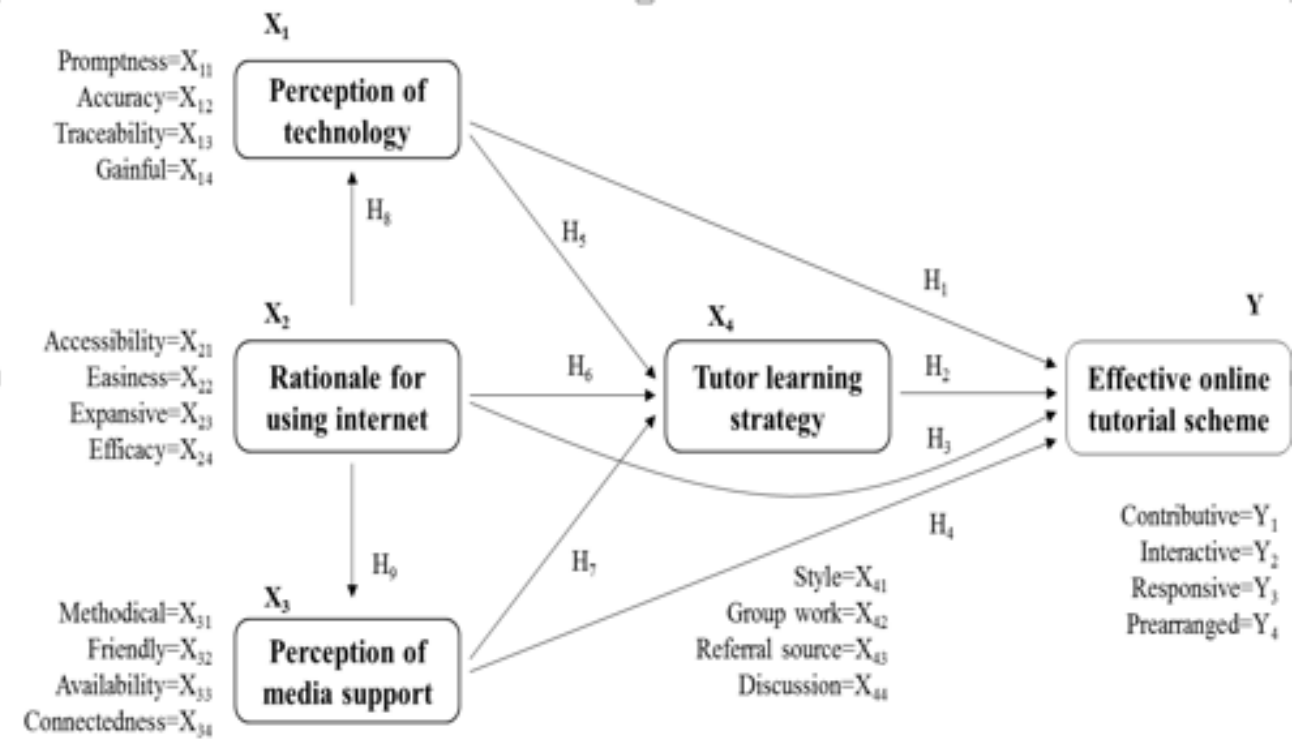

Figure 1. The operational framework

Variables are explored through questionnaire following Tjiptono and Chandra (2011). Six hundred questionnaires were provided and distributed to 5,500 Universitas Terbuka students under scholarship program through entirely 39 operating regional offices all over Indonesia. A survey is started to assemble acquired data (Fowler, 2014). A purposive sampling technique for qualitative procedure was chosen to determine eligible resource persons as experts in the study. Proportional sampling technique was preferred to determine eligible respondents for quantitative purpose by providing 600 questionnaires (Cochran, 1977; Sugijono, 2012). Each regional office acquires 15 set of questionnaires to be completed by selected students during March 2017.

After cautiously verifying, $\mathbf{2 8 3}$ out of $\mathbf{6 0 0}$ distributed questionnaires are finally completed and processed. SEM is then applied to distinguish the pattern, power and behavioral relations amongst all variables and dimensions engaged as the reflection of those 283 complete returned questionnaires (Hair, Black, Babin \& Anderson, 2009). Processed data were then arranged in the form of related figure and table completed under Lisrel version 8.80 as the end upshots of the study (Wijayanto, 2008).

The study therefore scrutinizes nine hypotheses (Figure 1). They are: effective online tutorial is influenced by perception of technology $\left(H_{1}\right)$, tutor learning strategy $\left(H_{2}\right)$, rational for using Internet $\left(\mathrm{H}_{3}\right)$, and perception of media support $\left(\mathrm{H}_{4}\right)$. Additionally, tutor learning strategy is influenced by perception of technology $\left(\mathrm{H}_{5}\right)$, rational for using Internet $\left(\mathrm{H}_{6}\right)$, and perception of media support $\left(\mathrm{H}_{7}\right)$; perception of technology $\left(\mathrm{H}_{8}\right)$ and perception of media support $\left(\mathrm{H}_{9}\right)$ are also influenced by rational for using Internet.

\section{RESULTS AND DISCUSSIONS}

Before depicting the final quantitative results, it is valuable to show the characteristics of respondents as illustrated in Table 2 . This will amplify our understanding related to the qualitative and quantitative procedures utilized sequentially. The results of analyses are detailed in the following interpretation accordingly with relevant figure and table. 
Table 2. Respondent characteristics

\begin{tabular}{|c|c|c|c|c|}
\hline Faculty & $\begin{array}{r}\text { Social \& Political } \\
\text { Science }=30 \%\end{array}$ & $\begin{array}{r}\text { Mathematics \& } \\
\text { Science=32\% }\end{array}$ & Economics $=38 \%$ & $\begin{array}{r}\text { Total } 100 \% \\
\text { [283 students] }\end{array}$ \\
\hline \multirow{2}{*}{$\begin{array}{c}\text { Regional } \\
\text { Offices } 38 / 40\end{array}$} & Sumatra $[10]=10$ & Java-Bali[13]=13 & Borneo [5]=4 & Celebes $[5]=5$ \\
\hline & Papua [2]=2 & Nusa $T[2]=2$ & Molluca [2]=2 & Overseas $[1]=0$ \\
\hline \multirow{2}{*}{2016 GPA } & $0.00-0.99=0 \%$ & $1.00-1.49=2 \%$ & $1.50-1.99=8 \%$ & $2,00-2,49=32 \%$ \\
\hline & $2.50-2.99=23 \%$ & $3.00-3.49=14 \%$ & $3.50-3.99=15 \%$ & $4.00=6 \%$ \\
\hline $\mathbf{A g e}_{(Y e a r)}$ & $\leq 20=43 \%$ & $21-23=46 \%$ & $24-26=11 \%$ & $\geq 27=0.00$ \\
\hline $\begin{array}{l}\text { Length of } \\
\text { Study }\end{array}$ & $\leq 2$-year $=23 \%$ & $3-$ year $=46 \%$ & 4 year $=31 \%$ & $\geq 5$ year $=0 \%$ \\
\hline $\begin{array}{l}\text { Marrital } \\
\text { Status }\end{array}$ & $\begin{array}{l}\text { Yes }=9 \% \\
\text { No }=91 \%\end{array}$ & If yes, children & $\begin{array}{r}\text { Yes }=18 \% \\
\text { No }=82 \%\end{array}$ & \\
\hline Occupation & Full time $=17 \%$ & Part time $=12 \%$ & None $=61 \%$ & \\
\hline Gender & Female $=61 \%$ & Male $=39 \%$ & & \\
\hline
\end{tabular}

Having observed the characteristics of respondents as illustrated in Table 2, we are now moving to the results of SEM analysis especially on the results of hypotheses assessment and the loading factors analysis as illustrated in Figure 2.

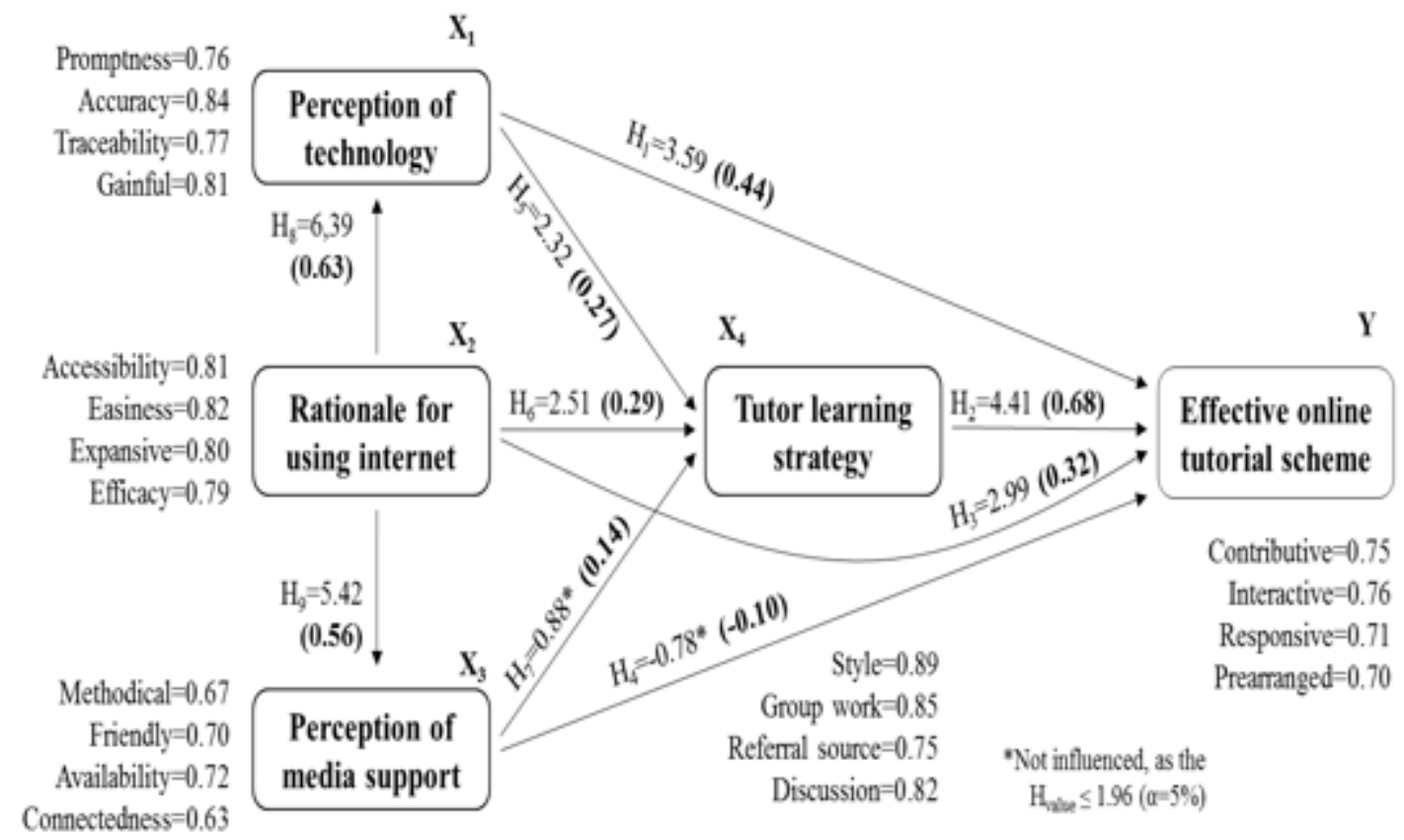

Figure 2. Results of hypotheses and the loading factors

Before describing and interpretating the results, it was confirmed under SEM output that the data is statistically valid and reliable. This implies that further step can be performed. Figure 2 obviously exposes that two out of nine hypotheses scrutinized are not validated by the analysis. They are: (1) perception of media support to effective online tutorial $\left(X_{3}\right.$ to $Y$ where $H_{4}=-0.78$ ) and (2) perception of media support to tutor learning strategy $\left(X_{3}\right.$ to $X_{4}$ where $H_{7}=0.88$ ). These two hypotheses are not authenticated by the analysis since the $t_{\text {values }} \leq 1.96$ (for $a=5 \%$ ). This means that statistically the effectiveness of an online tutorial scheme and tutor learning strategy are not positively and significantly influenced by perception of media support respectively. We will observe later whether or not the gap found in this stage is in a highly contradictory degree; whether they differ in conceptual and/or operational frameworks or partly only in the rank of the dimensions (in a lower level of meaning). 
In additions, the other seven hypotheses are positively and quite significantly validated by the analysis. They are: (1) $\mathrm{H}_{1}=3.59$ (perception of technology to effective online tutorial; $X_{1}-Y$ ), (2) $\mathrm{H}_{2}=4.41$ (tutor learning strategy to effective online tutorial; $\mathrm{X}_{4}-\mathrm{Y}$ ), (3) $H_{3}=2.99$ (rational for using Internet to effective online tutorial; $X_{2}-Y$ ), (4) $H_{5}=2.32$ (perception of technology to tutor learning strategy; $\left.X_{1}-X_{4}\right),(5) H_{6}=2.51$ (rational for using Internet to tutor learning strategy; $\left.X_{2}-X_{4}\right),(6) H_{8}=6.39$ (rational for using Internet to perception of technology; $X_{2}-X_{1}$ ) and (7) $H_{9}=5.42$ (rationale for using Internet to perception of media support, $\left.X_{2}-X_{3}\right)$, since all of the $t_{\text {values }} \geq 1.96$ (for $a=5 \%$ ). These imply that from statistical outlooks effective online tutorial support is significantly influenced by perception of technology, tutor learning strategy and rational for using Internet. Besides, tutor learning strategy is influenced by perception of technology and rational for using Internet; rational for using Internet influences both perception of technology and perception of media support.

Having confirmed the results of hypotheses testing, we are now in the position of relating the loading factors behavior. They are applied to tangibly discern the relations power of each of the participating variables and their comportments. They are accomplished under SEM, in the frame of factors affecting effective online tutorial support, to work out the end results by following Wijayanto (2008) and Hair, Black, Babin and Anderson (2009). Now, let us focus again on Figure 2 . There are five details need to be methodically elaborated prior to concluding the final ends under the quantitative approach.

The first is related to the utmost influential factor to the effective online tutorial variable. The analysis obviously confirmed that tutor learning strategy $\left(X_{4}\right.$ to $Y=0.68$ ) is the most influential factor to effective online tutoring program then successively followed by perception of technology $\left(X_{1}\right.$ to $\left.Y=0.44\right)$ and rational for using Internet $\left(X_{2}\right.$ to $\left.Y=0.32\right)$; whereas perception of media support was excluded by the analysis. This means that most respondents considered strategy of tutor and how they managed activities in each and every session of tutorial session was exceptionally a big deal. This also implies that effective online tutorial support to certain extent was forced by external force and out of student control; as rational for using Internet, perception of technology, and perception of media factors are intrinsically within student controls.

Besides, the dimensions within tutor learning strategy placed style $\left(X_{41}=0.89\right)$ by most respondents as the highest aspect in controlling tutor learning strategy. This is consistent to what was previously obtained from the qualitative inquiry. The other three dimensions are successively described as follows: group work $\left(X_{42}=0.85\right)$, discussion $\left(X_{44}=0.82\right)$ and referral source $\left(X_{43}=0.72\right)$. These results imply that most of respondents believed tutor strategy, especially the style, was able to motivate students to be more involved in the group work, induce discussion among themselves and search for related academic source by their own way and available time. Reasonably, these are also the general impressions obtained from the preceding qualitative inquiry.

The second is associated with factors affecting tutor learning strategy $\left(\mathrm{X}_{4}\right)$. Conceptually, it was influenced by perception of technology $\left(X_{1}\right)$, rational for using Internet $\left(X_{2}\right)$, and perception of media support $\left(X_{3}\right)$. Having carefully assessed, however, perception of media support $\left(X_{3}\right)$ had no effect on the tutor learning strategy $\left(X_{4}\right)$. Tutor learning strategy was influenced by rational for using Internet $\left(X_{2}=0.29\right)$ and then followed by perception of technology $\left(X_{1}=0.27\right)$. This means that rational for using Internet clearly had more effects than that of perception of technology with respect to the tutor learning strategy. Students positioned rational for using Internet is more likely to have influenced on the online tutorial support directly and/or indirectly as compared to the perception on the technology.

Some respondents not only agreed upon quantitative effects at the variable level but also in the ranks of the dimensions. Respondents concurred that by having a good sense on rational for using Internet will certainly help them to get hold the easiness $\left(X_{22}=0.82\right)$, 
access $\left(X_{21}=0.80\right)$, expansion $\left(X_{23}=0.80\right)$, and efficacy features $\left(X_{24}=0.79\right)$ related to the chances of obtaining interactive and contributive online tutorial support. Moreover, respondents viewed accuracy $\left(X_{12}=0.84\right)$ as the most influential dimension of rational for using Internet and then followed by gainful $\left(X_{14}=0.81\right)$, traceability $\left(X_{13}=0.77\right)$, and promptness respectively $\left(X_{11}=0.76\right)$ in conjunction with an interactive and contributive online tutoring support.

The third consequence, on the rational for using Internet which affected perception of technology $\left(X_{2}\right.$ to $\left.X_{1}=0.63\right)$ and perception of media support $\left(X_{2}\right.$ to $\left.X_{3}=0.56\right)$. These two outputs show that perception of technology was much more affected by rational for using Internet rather than that of perception of media support. Most of respondents learned that to get advantages of interactive and contributive online tutorial support are more likely to have achieved by having a good rational for using Internet as compared to perception of media support. They were true in most cases. Given that to certain extent the ICT were characterized by various advantages, student would be more entertained by the online tutorial support. It is essentially critical to possess the perception of media support but in fact it had no effect on the online tutorial in this inquiry.

The fourth is relationships between perception of media support with tutor learning strategy and effective online tutorial scheme. It was actually disturbing that under statistical procedure the perception of media support has no effects to both tutor learning strategy as the moderating and effective online tutorial scheme as the dependent variables. Theoretically, at least perception of media support influenced either effective online tutorial supports directly or indirectly through the moderating variable, i.e., tutor learning strategy. It seems that further prudent inquiry is necessary to envisage how and why it unpredictably just goes like that.

The fifth is a gap between qualitative versus quantitative results. Initially, it was established four main variables associated with the effective online tutorial support. Based upon that basis, the conceptual framework was developed to be quantitatively validated. Nine hypotheses were statistically scrutinized. After all, two of them were not statistically validated by the analysis. This implies that the quantitative results were not comparatively harmonious with the qualitative structure as formerly established.

Having perceived the quantitative and qualitative upshots, the results were distinct and somewhat contradicting one another. Is it so? Effective online tutorial support was not directly influenced by one of independent variable. Under quantitative routines, there are three motives why it might happen so. The first is on the elaboration process of the variables. The second is on the transformation process of variables into dimensions as the bases to construct questionnaires. The third is on the data collection processes. These deduce that further guarded inquest under quantitative procedure is significant implemented by noticing those three aspects previously explained. Despite the distinctive ends did take place, the quantitative outcomes are still useful (tutor learning strategy is positively a hint to effective online tutorial support). From qualitative procedure, it implies that the online tutorial can be firmly disclosed as summarized in Table 1.

Prior to justifying the closing line from qualitative versus quantitative results, it is reasonable to think over whether the SEM output is in 'good fit' category or not. If yes, it is dependable to consider the hypotheses and engender the loading factors to confirm the power of all behavioral interrelations. The analysis confirmed that they actually are in the 'good fit' category except for Normal Fit Index (NFI) as illustrated in Table 3; NFI was however in a marginal fit category. This implies that the quantitative model validated is methodically dependable. The conceptual and operational framework implied having a substantial and technical harmony in theoretical and methodological outlooks. 
Table 3. Goodness of fit of the tested framework

\begin{tabular}{rrrc}
\hline Goodness of Fit & Cut-off Value & Results & Notes \\
\hline RMSEA Root Mean Square Error Approximation & $\leq \mathbf{0 . 0 8}$ & $\mathbf{0 . 0 8}$ & Good Fit \\
RMSR Root Mean Square Residual & $<0.05$ or $<0.10$ & 0.74 & Good Fit \\
GFI Goodness of Fit & $\geq 0.90$ & 0.91 & Good Fit \\
AGFI Adjusted Goodness of Fit Index & $\geq 0.90$ & 0.94 & Good Fit \\
CFI Comparative Fit Index & $\geq 0.90$ & 0.96 & Good Fit \\
NFI Normal Fit Index & $\geq 0.95$ & $\mathbf{0 . 9 4}$ & Marginal Fit \\
RFI Relative Fit Index & $\geq 0.90$ & $\mathbf{0 . 9 3}$ & Good Fit \\
\hline
\end{tabular}

Despite one goodness of fit is in marginal category (the NFI; Table 1), it is still helpful to utilize them as a point of reference to bridge understanding between the qualitative and quantitative endings. Three underlying evaluations need to be opened up to make use of the corollaries. The first consequence is the dispute on the different results under exploratory-design used. The second is reason adjacent to respondent characteristics. The third is on the implication of findings for future consideration if conducting further research with a comparable theme.

After completing the procedures, tutor learning strategy is mutually supporting with rational for using Internet and perception of technology along with their dimensions (as two independent variables). Likewise, moderating variable partly interconnected with independent variables. Remarkably, despite perception of media support has no effect to the online tutorial support, it was influenced by rational for using Internet. Fortunately, independent variables are interrelated one another with significant power of relations. This implies that the qualitative and quantitative results are considerably varies; however, it is providential are not absolutely contradict each other.

Exploratory-design, as part of mixed methods, was conducted by collecting and analyzing qualitative data first and then building the quantitative structure prior to interpretation (Creswell \& Clark, 2011). It aims at measuring qualitative exploratory findings. Prior to building operational framework under quantitative procedure, the conceptual framework (qualitative outcomes) should be first established as the framework of the study that will be statistically scrutinized afterwards. Therefore, connecting the two strands with respect to theoretical and/or instrumental elaboration become crucial details. In fact, the end results show that two out of nine hypotheses established are imperfectly verified by the analysis. Besides, the order of dimensions is partly not in harmony as well. Again, this is to make more observable that the quantitative approach is still unable to perfectly approve prior qualitative exploratory findings.

Referring to the respondent characteristics (Table 2), it can be definitely enlightened that most of respondents are young and they were highly literate in ICT, full time students and having a good academic performance (GPA) as well. These facts explain why most respondents did not regard media support aspects, as one of independent variable, as a chief clue leading to effective online tutorial support; as well as to the moderating variable, i.e., tutor learning strategy. What is primarily critical to them as distance learners and users is how tutors plan, organize and monitor all tutorial activities in a good and well-regulated quality procedure primarily in providing and maintaining an online tutoring program accordingly.

Anticipating corresponding research for further judgement is prominent to be explored. The magnitude of respondents is not solely restricted to the scholarship students but also by welcoming all other 297 thousand students. Having involved them, it will enlarge the effects obtained with respect to the framework resulted from qualitative inquiry; related to searching for the determinant of effective tutorial comprehensively under ODL setting. Sensible insight is required to be identified to avoid restraint retrieving harmony between 
qualitative and quantitative conclusion. Most of all, searching for and adopting appropriate methods are certainly urgent to define an authentic determinant of effective online tutorial service that mutually supporting each other, both under qualitative and quantitative procedures.

\section{CONCLUDING REMARKS}

The results of this inquiry encountered slight considerable variations between what had been achieved from qualitative routines as opposed to the quantitative approach. Two out of nine hypotheses assessed are not validated by the analysis. This implies that established qualitative frame is imperfectly approved by the quantitative approach. Yet, they only differ, not necessarily contradicting in a high influence. The end result is therefore still useful for the University and related stakeholders in respecting critical variables that should be carefully taken into account to provide effective online tutorial scheme along with their dimensions in accordance with student needs.

It is worth to note that most respondents classified tutor learning strategy in the first spot as a tip-off point. This is becoming more crucial, according to Lee and Martin (2017), despite online discussions are a common component of most online courses, how to engage students in online discussions has been an everlasting challenge. This entails that the University should take this upshot by spotting imaginable constraints which might be real, especially how to motivate students being much more active in a group work and discussion through common acceptable style of tutors. The University is wellrecommended to get ahead on four dimensions in this variable so that tutors would have comparable perception on that issue. Additionally, imagining this know-how is unanimously typical in a wide-ranging of ODL ambiance, the management, faculty, and tutors would then be well-advised to reflect on the variables discussed along with their associated dimensions explained earlier. It is aimed at offering beliefs that tutor learning strategy grows to be straightforward aptitude to endeavor great online tutoring scheme as expected by students for their academic performance and persistence as distance learners (Sembiring, 2015). Although online tutoring idea is phenomenal, primarily in ODL environment, because of its flexibility and convenience, it is truly important to address those issues that adversely impacting on retention with respect to the success of the vast majority of students.

Further comprehensive study should be aggressively and regularly organized in terms of instructional design necessity and learning styles endorsement relative to the virtues of online tutoring structure in ODL perspectives with much broader perspectives. All these endeavors lead to satisfying student need and expectation.

\section{BIODATA and CONTACT ADDRESSES of AUTHOR}

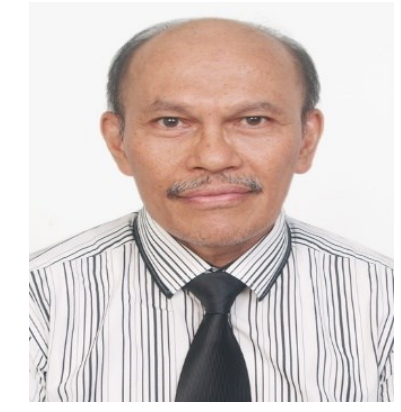

Maximus Gorky SEMBIRING, a Doctor in Educational Management, is a senior academic of Universitas Terbuka. He is currently the Director of Research Center. His research interest mainly focuses on student support services. He has been in the University for more than 33 years. In the last six years, he authored 12 articles published in the international journals and/or presented in the International (world) Conferences. He was awarded four Best Paper Awards by the Asian Association of Open Universities (2014, 2015, 2016 and 2017). He was also awarded two Best Paper 
Awards by the International Council for Open and Distance Education (2013 and 2015). Moreover, in 2017, he was awarded three Best Paper Awards, i.e., two from the Educational Technology World Conference, Indonesia and one from the International Conference on Open and Innovative Education hosted by the Open University of Hong Kong.

Dr. Maximus Gorky SEMBIRING

Faculty of Education and Teacher Training, Universitas Terbuka

Jalan Cabe Raya, Pondok Cabe,Pamulang, Tangerang Selatan, INDONESIA 15418

Phone: +62 816878444

E-mail: gorkysembiring@gmail.com

\section{REFERENCES}

Bean, J. P. (1985). Interaction effects based on class level in an exploratory model of college student dropout syndrome. American Educational Research Journal, 22(1), 35-64.

Benham, C. (2002). Training effectiveness, on-line delivery, and the influence of learning style. Proceedings of the 2002 ACM Special Interest Group on Computer Personnel Research Conference, 41-46. Kristiansand, Norway.

Bliwise, N. (2005). Web-based tutorials for teaching introductory statistics. Journal of Educational Computing Research, 33(3), 309-325.

Bolliger, D., \& Supanakorn, S. (2011). Learning styles and student perceptions of the use of interactive online tutorials. British Journal of Educational Technology, 42(3), 470-481.

Cheng, J., \& Swanson, Z. (2011). An examination of the effects of web-based tutorials on accounting student learning outcomes. Review of Higher Education and SelfLearning, 4(10), 14-28.

Cochran, W. G. (1977). Sampling techniques. $3^{\text {rd }}$ Ed. New York: John Wiley \& Sons.

Creswell, J. W. \& Clark, V. L. P. (2011). Designing and conducting mixed-methods Research. 2nd Ed. Los Angles: Sage Publication.

Devine, J., \& Lokuge, W. (2012). Engaging distance students through online tutorials. Proceedings of 2012 AAEE Conference, Melbourne, Australia.

Dawson, S. (1998). Effective tutorial teaching. Melbourne: RMIT Publishing.

Elicker, J., O'Malle, A., \& Williams, C. (2008). Does an interactive Web-CT site help students learn? Teaching of Psychology, 35, 126-131.

Fowler, F. J. Jr. (2014). Survey research methods. $5^{\text {th }}$ Ed. Los Angeles: Sage Publication.

Guy, R. S., \& Lownes-Jackson, M. (2012). Assessing effectiveness of web-based tutorials using pre-test and post-test measurements. Interdisciplinary Journal E-Learning \& Learning Objects, 8, 15-38.

Hair, Jr., J. F., Black, W. C., Babin, B. J., \& Anderson, R. E. (2009). Multivariate data analysis with readings. $7^{\text {th }}$ Ed. New Jersey: Prentice Hall.

Jain, A. (2006). Students' perceptions of workshop based introductory macro-economic tutorials: A survey. Economic Papers, 25(3), 235-251.

Keefe, J. (1979). Learning style: An overview. In J. W. Keefe (Ed.), Learner learning styles: Diagnosing and prescribing programs. Reston: NASSP.

Kobayashi, M. (2017). Students' media preferences in online learning. Turkish Online Journal of Distance Education, 18(3), 4-15. 
Koch, C., \& Gobell, J. (1999). A hypertext based tutorial with links to the Web for teaching statistics and research methods. Behavior Research methods, Instruments \& Computers, 31, 7-13.

Lee, J., \& Martin, L. (2017). Investigating Students' Perceptions of Motivating Factors of Online Class Discussions. International Review of Research in Open and Distributed Learning, 18(5). DOI: http://dx.doi.org/10.19173/irrodl.v18i5.2883 (Accessed 8 September 2017).

Lee, W., Courtney, R., \& Balassi, S. (2010). Do online homework tools improve student results in principles of microeconomics courses? The American Economic Review, 100(2), 286-287.

Lenz, L. (2010). The effect of a web-based homework system on student outcomes in the $1^{\text {st }}$ year mathematics course. Journal of Computers in Mathematics \& Science Teaching, 293, 233-246.

MacKinnon, G., \& Williams, P. (2006). Models for integrating technology in higher education: The physics of sound. Journal of College Science Teaching, 35(7), 2225.

Mbatha, B. (2015). A paradigm shift: adoption of disruptive learning innovations in an ODL environment - the case of the University of South Africa. International Review of Research in Open and Distributed Learning, 16(3), 218-232.

Mitchell, M., \& Jolley, J. (1999). The correlation: A self-guided tutorial. Teaching of Psychology, 26, 298-299.

Osborn, D. (2010). Do print, Web-based or blackboard integrated tutorial strategies differentially influence student learning in an introductory psychology class? Journal of Instructional Psychology, 37(3), 247-251.

Price, L., Richardson, J. T. E., \& Jelfs, A. (2007). Face-to-face versus online tutoring support in distance education. Studies in Higher Education, 31(1), 1-20.

Retna, K., Chong, E., \& Cavana, R. (2009). Tutors and tutorials: Students' perceptions in a New Zealand university. Journal of Higher Education Policy and Management, 31(3), 251-260.

Rosell-Aguilar, F. (2007). Changing tutors roles in online tutorial support for ODL through audio-graphic SCMC. The JALT CALL Journal, 3(1-2), 81-94.

Rustam, Haliman, H., Susanty, E., \& Sembiring, M. G. (2015). Exposing the gist of effectual an online tutorial support. Paper presented at the 29th Annual Conference of the Asian Association of Open Universities (AAOU), hosted by Open University Malaysia, Kuala Lumpur, 30 November-2 December 2015.

Sembiring, M. G. (2014). Modeling determinants of student retention in distance education institutions. International Journal of Continuing Education \& Lifelong Learning, 6(2), 15-18.

Sembiring, M. G. (2015). Student satisfaction and persistence: Imperative features for retention in ODL. Asian Association of Open University (AAOU) Journal, 10(1), June 2015, 1-11.

Shin, W. S., \& Kang, M. (2015). The use of a mobile learning management system at an online university and its effect on learning satisfaction and achievement. International Review of Research in Open and Distributed Learning, 16(3), June 2015, 110-130.

Sugiyono. (2012). Metode penelitian kombinasi. Bandung: Penerbit Alfa Beta.

Susilo, A. (2014). Emerging technologies acceptance in online tutorials: tutors' and students' behavior intentions in higher education. Open Praxis, 6(3), Jul-Sep 2014, 257-274. 
Sweeney, J., \& Ingram, D. (2001). A comparison of traditional and web-based tutorials in marketing education. Journal of Marketing Education, 23(1), 55-62.

Tallmadge, W., \& Chitester, B. (2010). Integrating concepts using online tutorials in a freshman chemistry course: Transformative Dialogues. Teaching and Learning Journal, 4(2), 1-7.

Tinto, V. (1993). Leaving college: rethinking causes and cures of student attrition. $2^{\text {nd }}$ Ed. Chicago: University of Chicago.

Tjiptono, F., \& Chandra, G. (2011). Service, quality \& satisfaction. Yogyakarta: Andi.

Universitas Terbuka. (2015). Strategic and operational planning of Universitas Terbuka 2014-2021. Tangerang Selatan: Universitas Terbuka.

Universitas Terbuka. (2017). Rector's office yearly report. Tangerang Selatan: Universitas Terbuka.

Varnhagen, C., \& Digdon, N. (2002). Helping students read reports of empirical research. Teaching of Psychology, 29, 160-164.

Wijayanto, S.H. (2008). Structural equation modeling - Lisrel 8.80. Yogyakarta: Penerbit Graha IImu.

Wilson, S., \& Harris, A. (2002). Evaluation of the Psychology Place: A web-based instructional tool for psychology courses. Teaching of Psychology, 29, 165-168.

Zhang, W. Y., Perris, K., \& Yeung, L. (2005). Online tutorial support in open and distance learning: students' perceptions. British Journal of Educational Technology, 36(5), 789-804. 